\title{
SIZE REDUCTION OF KLOPFENSTEIN-BALUN TRANSFORMER FOR BALANCED ANTENNAS
}

\author{
Shailendra P. Shastri ${ }^{1 a}$, Ravish R. Singh ${ }^{2 b}$ and Sandeep Y. Pawar ${ }^{3 c}$
}

${ }^{a}$ Faculty of Engineering, Pacific Academy of Higher Education and Research University, Udaipur, Rajasthan313003, INDIA. Email: shastri_shailendra@rediffmail.com

bAcademic Advisor, Thakur Educational Trust, Mumbai-400068, INDIA. Email: ravishrsingh@yahoo.com 'Department of Electronics and Telecommunication Engineering, Vidyavardhini's College of Engineering and Technology, Vasai, Maharashtra-401202, INDIA. Email: sandeepyp@yahoo.co.in Corresponding author: shastri_shailendra@rediffmail.com

Received: $7^{\text {th }}$ May $2019 \quad$ Accepted: $11^{\text {th }}$ Mar 2020

Published: $28^{\text {th }}$ Feb 2021

DOI: https://doi.org/10.22452/mjs.vol40no1.5

ABSTRACT A compact broadband BALUN transformer is designed using the Klopfenstein taper line transformer approach to transform a $50 \Omega$ impedance into $100 \Omega$. To reduce the length of the conventional BALUN, a straight microstrip (MS) line is modified as a curved MS line. The proposed compact BALUN is $56.7 \%-73 \%$ smaller w.r.t the straight conventional BALUN but at the cost of a $4.5 \%-13 \%$ reduction in the overall band. The conventional BALUN has a measured $\%$ bandwidth of 165 , while the compact BALUN has a result of 159 . The measured results agree with the simulated results.

Keywords: Unbalanced line, BALUN, balanced line, coplanar stripline, \% bandwidth and tapered microstrip line.

\section{INTRODUCTION}

R. W. Klopfenstein proposed an improved design of tapered transmission lines in 1956, and since then, this technique has been used to improve the performance of high-frequency devices. It is an impedance matching transmission line to keep the reflection coefficient at the minimum over a particular passband (Klopfenstein, 1956). This tapered line is an important part of a BALUN transformer when it comes to the transformation of impedance and conversion from an unbalanced line into a balanced one. The BALUN transformer is one of the most important elements when it is required to feed a balanced antenna using an unbalanced feed. Unfortunately, the highfrequency line available to feed balanced antennas is unbalanced in nature. Therefore, when an unbalanced feed is directly connected to a balanced antenna, the current entering the antenna and the current returning from the antenna differ. This action changes the antenna impedance seen by the feed line and is different from the designed impedance of the antenna. The problem can be resolved using a BALUN transformer between the antenna feed point and the single-ended transmission line.

There are many printed BALUNs proposed in the literature. A broadband coplanar waveguide (CPW) to coplanar strip (CPS) transmission line transition exhibited very good performance up to $55 \mathrm{GHz}$ (Anagnostou et al., 2008). A wide band from $1.1 \mathrm{GHz}$ to $10.5 \mathrm{GHz}$ was achieved using a transition from a multisection microstrip (MS) line to a CPS line terminated with a quarter wavelength radial stub (Tu \& Chang, 2006). A tapered Klopfenstein line was used to match 
impedances between a Ka-band pillbox window and a Helix-TWT. The designed transformer gives excellent performance across $30 \mathrm{GHz}$ to $34 \mathrm{GHz}$ (Resley \& Song, 2012). The performance of the Klopfenstein taper line for various loads and lengths was investigated to reduce the maximum group delay with an acceptable variation of the impedance bandwidth (Ruvio \& Ammann, 2008). BALUNs have also been designed to feed slot antennas, and one such BALUN was a fourth-order modified Marchand BALUN covering a band from $0.5 \mathrm{GHz}$ to $5.5 \mathrm{GHz}$. This wideband performance was achieved using a slot line to MS line transition with radial stubs (Maksimovitch et al., 2007). A dipole antenna with both arms on opposite sides of a substrate was excited using an asymmetric MS line BALUN transformer. This BALUN comprised a taper ground plane connected to one arm of the dipole and the MS line of the BALUN connected to the other arm of the dipole present on the other side of the substrate (Bah, 2016). Impedance transformation using a taper transmission line technique is not restricted to printed technology but also extends to the coaxial transmission line (Vega et al., 2011). A larger band of $30: 1$ can be achieved using multiple transitions from MS to coplanar waveguide and back to the MS line (Meng et al., 2016).

All the previously designed BALUNs or taper transformer structures are geometrically straight, and thus, occupy relatively large onboard space. Here, we propose a technique that can reduce the size of straight BALUNs or taper line transformer structures. The proposed broadband BALUN is much smaller compared with conventional BALUNs. The conventional straight structure is modified with an equivalent curved structure, and onboard space is saved. The complete design of the conventional BALUN is discussed along with the design technique of the proposed BALUN. The conventional and proposed BALUNs are compared in terms of bandwidth and size. The BALUN is designed to transform an impedance of $50 \Omega$ to $100 \Omega$, but the solution can also be applied to other impedances.

The remainder of the paper proceeds as follows: Section 2 introduces a conventional way of designing a wideband BALUN using the Klopfenstein taper line technique. Section 3 is dedicated to modification in the conventional taper BALUN to reduce its size. Finally, Section 4 provides the results and discussion for the implemented BALUN transformers.

\section{DESIGN OF A TAPERED BALUN}

To design a tapered BALUN, the FR-4 substrate is used with a thickness of $0.8 \mathrm{~mm}$. Figure 1 is a representation of a taper transmission line loaded with a load $\mathrm{Z}_{\mathrm{L}}$; in the figure, $\mathrm{Z}(\mathrm{z})$ is the characteristic impedance variation of the taper line, and $\mathrm{Z}_{0}$ is the characteristic impedance or reference impedance. The design of the BALUN is based on the Klopfenstein taper transformer, which is derived from a stepped Chebyshev transformer.

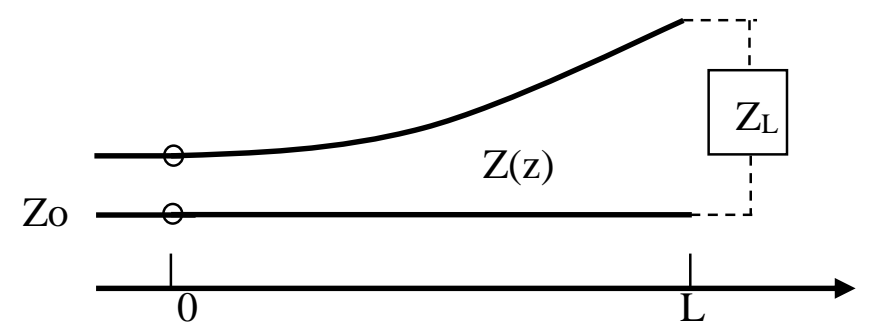

Figure 1. Taper transmission line loaded with load $Z_{L}$ and driven by reference impedance $Z_{0}$ 
The taper line transformer of length $\mathrm{L}$ is divided into $\mathrm{n}$ sections of different impedances to transform $\mathrm{Z}_{\mathrm{L}}$ into $\mathrm{Zo}$. The following Klopfenstein taper relation is used to determine the characteristic impedance variation of the taper section (Pozar, 1998):

$$
Z(z)=\frac{1}{2} \ln Z_{0} Z_{L}+\frac{\Gamma_{0}}{\cosh A} A^{2} \phi\left(\frac{2 z}{L}-1, A\right)
$$

where $0 \leq z \leq L$ (length of the taper line), $\mathrm{Z}(\mathrm{z})$ is the characteristic impedance variation along the line and $Z_{0}=50 \Omega$ and $Z_{L}=100 \Omega$.

The function $\phi(x, A)$ is defined as

$$
\phi(x, A)=-\phi(-x, A)=\int_{0}^{x} \frac{I_{1}\left(A \sqrt{1-y^{2}}\right.}{A \sqrt{1-y^{2}}} d y,
$$

where $I_{1}(x)$ is the modified Bessel function, and

$$
\begin{gathered}
A=\cosh ^{-1}\left\{\frac{\Gamma_{0}}{\Gamma_{m}}\right\}, \\
\Gamma_{0}=\frac{Z_{L}-Z_{0}}{Z_{L}+Z_{0}}, \\
\Gamma_{m}=\frac{\Gamma_{0}}{\cosh A},
\end{gathered}
$$

where $\Gamma_{m}$ is the maximum ripple in the passband of the transformer and is assumed by the designer. Moreover, $\Gamma_{0}$ is the reflection coefficient at zero frequency, and it is given by (4). The passband of the transformer is defined for $\beta L \geq A$.

The following equation is used to produce the relation between $\Gamma$ and $\beta L$, as shown in Figure 2:

$$
|\Gamma|=\frac{1}{2} \ln \left[\frac{Z_{L}}{Z_{0}}\right]\left[\frac{\sin \left(\frac{\beta L}{2}\right)}{\frac{\beta L}{2}}\right]^{2} .
$$

Here, $|\Gamma|$ is the magnitude of the reflection coefficient along the taper line and $\beta$ is the phase constant.

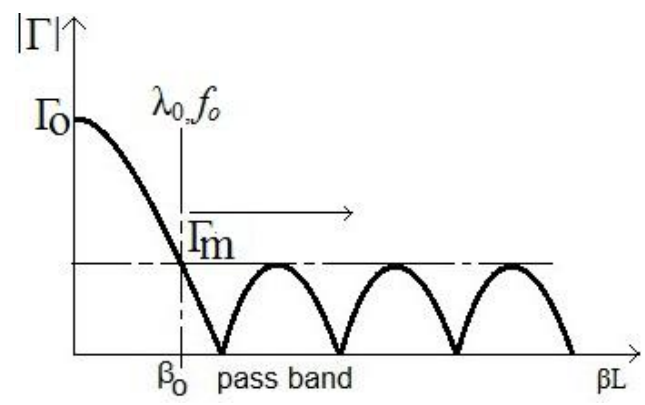

Figure 2. Reflection coefficient as a function of $\beta L$ for an $\mathrm{n}$ section Tchebycheff transformer 
In Figure $2, \beta_{0}$ is the phase constant for the largest wavelength $\lambda_{o}$ or the smallest frequency $f_{o}$ for which the reflection coefficient is $\Gamma_{m}$. It can be observed that $\Gamma_{m}$ is the maximum reflection coefficient in the passband. The largest wavelength is found using the relation for a known $L$ :

$$
\beta L=A=\beta_{0} L
$$

$\beta_{0}$ is expressed as

$$
\beta_{0}=\frac{2 \pi}{\lambda_{0}}
$$

Equation (7) also shows that the maximum operating wavelength of the taper line depends on the taper length $L$. A larger $L$ ensures a lower operating frequency in the passband for which the maximum reflection coefficient is $\Gamma_{m}$. Therefore, to have a lower operating frequency, the length of the taper line should be larger. Further discussion and simulations elaborate on the relations among $\Gamma_{m}, L$ and $\beta$. Figure 3 shows the behaviour of the reflection coefficient along the taper line for the assumed values of $\Gamma_{m}$ ranging from 0.01 to 0.03 . The taper line lengths were chosen as $3 \mathrm{~cm}$ and $5 \mathrm{~cm}$. From the figure, it can be observed that the variation in $\Gamma_{m}$ affects the least frequency in the passband.

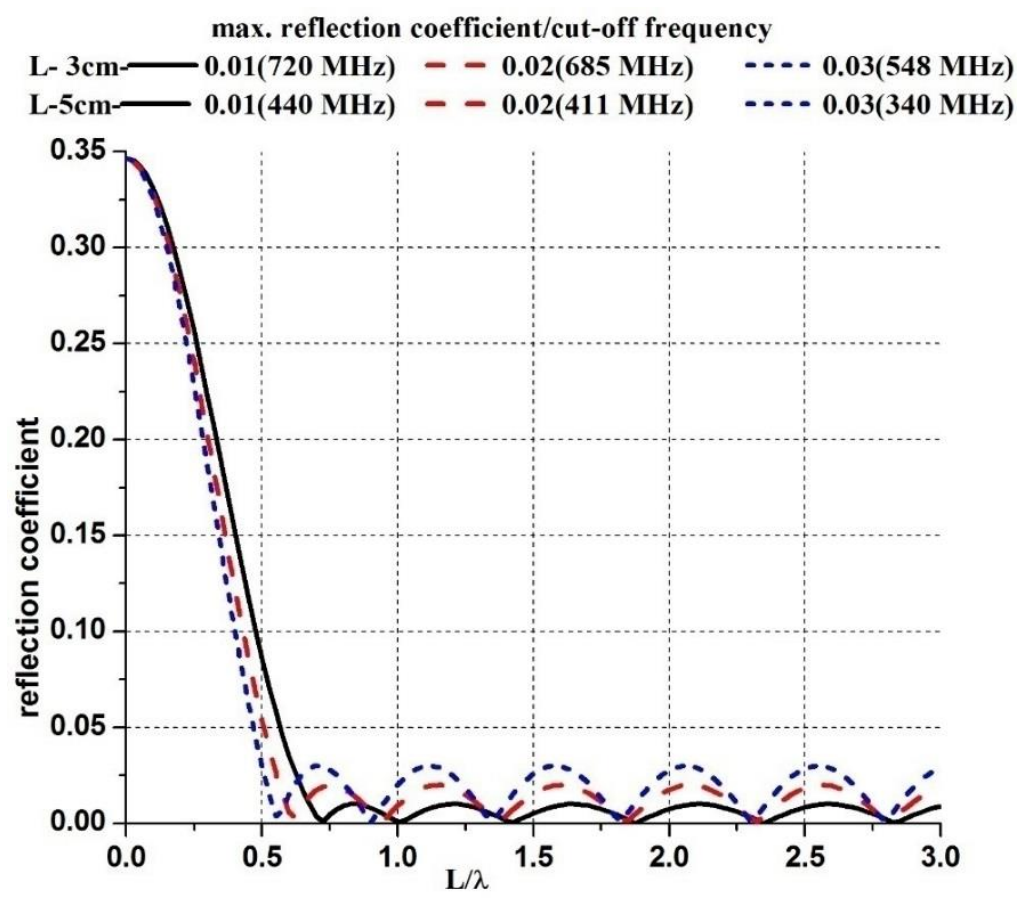

Figure 3. Behaviour of the reflection coefficient of taper line through calculation

The complete analysis of Figure 3 is tabulated in Table 1(a), and a summary of similar analysis for the taper line of length
$5 \mathrm{~cm}$ is tabulated in Table 1(b). The conclusions drawn from Figure 3 and Table 1 are as follows:

1) A larger value of $\Gamma_{m}$ reduces the minimum frequency in the passband. The minimum frequency in the passband can be calculated using 


$$
f_{0}=\frac{3 * 10^{8}}{\lambda_{0} \sqrt{\varepsilon_{r}}}
$$

Where $\sqrt{\varepsilon_{r}}$ is relative dielectric constant of the dielectric material FR-4. Therefore, the minimum frequency $f_{o}$ in the passband is inversely proportional to the length of $L$. This frequency can be calculated by selecting $L$ and using relations (3), (7), (8) and (9).

2) The operating frequency $f$ is much smaller than $f_{o}$ for the reflection coefficient $\Gamma$ of about $-10 \mathrm{~dB}$, as shown in the last column of Table 1. Furthermore, $f$ can be calculated from (6) and (9).

Table 1 (a). Summary of relations among $\Gamma_{m}, L$ and $\beta$

\begin{tabular}{cccccc}
\hline \multicolumn{6}{c}{$Z_{L}=100, Z_{0}=50, L=3 \mathrm{~cm}, \Gamma_{0}=0.333$} \\
\hline Sr. No & $\Gamma_{m}$ & $A$ & $f_{o} \mathrm{GHz}$ & $\Gamma_{m}(\mathrm{~dB})$ & $f_{@-10 \mathrm{~dB}}$ \\
\hline 1 & 0.01 & 4.23 & 3.7 & -40 & $800 \mathrm{MHz}$ \\
\hline 2 & 0.02 & 3.54 & 3.0 & -34 & $690 \mathrm{MHz}$ \\
\hline 3 & 0.04 & 2.85 & 2.5 & -28 & $550 \mathrm{MHz}$ \\
\hline
\end{tabular}

Table 1 (b). Summary of relations among $\Gamma_{m}, L$ and $\beta$

\begin{tabular}{cccccc}
\hline \multicolumn{5}{c}{$Z_{L}=100, Z_{0}=50, L=5 \mathrm{~cm}, \Gamma_{0}=0.333$} \\
\hline Sr. No & $\Gamma_{m}$ & $A$ & $f_{o} \mathrm{GHz}$ & $\Gamma_{m}(\mathrm{~dB})$ & $f_{@}-10 \mathrm{~dB}$ \\
\hline 1 & 0.01 & 4.23 & 2.2 & -40 & $430 \mathrm{MHz}$ \\
\hline 2 & 0.02 & 3.54 & 1.85 & -34 & $410 \mathrm{MHz}$ \\
\hline 3 & 0.04 & 2.85 & 1.49 & -28 & $340 \mathrm{MHz}$ \\
\hline
\end{tabular}

In this section, a taper line transformer is designed using data from Table 1a; this is summarised in Table 2. The same transformer is modified to have a compact size in the next section.
The taper line transformer under consideration has a $-40 \mathrm{~dB}\left(\Gamma_{m}\right)$ reflection coefficient from $3.7 \mathrm{GHz}$ onwards, whereas the $-10 \mathrm{~dB}$ frequency is at $800 \mathrm{MHz}$.

Table 2. Assumed design data and simulated results of taper line.

\begin{tabular}{cccccc}
\hline$Z_{L}$ & $Z_{0}$ & $\Gamma_{m}$ & $f_{o}$ & $f_{®-10 d B}$ & $L$ \\
\hline $100 \Omega$ & $50 \Omega$ & $0.01 /-40 \mathrm{~dB}$ & $3.7 \mathrm{GHz}$ & $800 \mathrm{MHz}$ & $3 \mathrm{~cm}$ \\
\hline \multicolumn{2}{l}{ Simulated results } & $-21.7 \mathrm{~dB}$ & $3.7 \mathrm{GHz}$ & $624 \mathrm{MHz}$ & $3 \mathrm{~cm}$ \\
\hline
\end{tabular}

The complete BALUN structure comprising the taper line transformer and a CPS line is shown in Figure 4. The taper line is the MS line, and it is unbalanced in nature, whereas the CPS line is balanced. In this section, a taper line is simulated to transform $50 \Omega$ to $100 \Omega$ impedance. The same taper line transformer is added with a CPS line of $100 \Omega$ to complete the BALUN transformer.
The length of the taper line is $30 \mathrm{~mm}$, and it is divided into 20 sections, each of which is $1.5 \mathrm{~mm}$ long. The width of each section is different as these small lines represent different impedances along the taper line. The impedance of the first section is $51 \Omega$, marked as ' 1 ' in Figure 4 . The impedance of the last section is $98.9 \Omega$, marked as ' 20 '. The width of the first section is $1.44 \mathrm{~mm}$ and that of the last section is $0.32 \mathrm{~mm}$. Section ' 0 ' in Figure 4 
is a $50 \Omega \mathrm{MS}$ line of $5 \mathrm{~mm}$ in length; and it is used to accommodate SMA connectors. The electrical behaviour of the taper line is shown in Figure 5, and the results are summarised in Table 2. The passband is available from $3.7 \mathrm{GHz}$ with a reflection

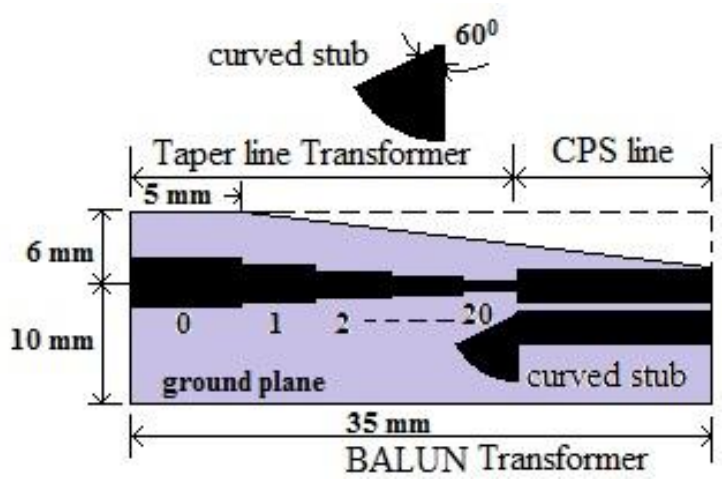

Figure 4. Structure of BALUN transformer using a taper line

To change the taper geometry into a BALUN, a CPS line of $100 \Omega$ is added. The gap between the CPS lines is $0.25 \mathrm{~mm}$, and the width of the CPS is $1.44 \mathrm{~mm}$. The CPS line is added with a broadband radial stub which also plays an important role in changing the orientation of the electric field (Tu \& Chang, 2006). The band considered for the analysis is $1 \mathrm{GHz}$ to $9 \mathrm{GHz}$. Therefore, the calculated radius of the curved stub is approximately $8.5 \mathrm{~mm}$, which is $1 / 4^{\text {th }}$ of the wavelength at the centre frequency of the assumed band. The radius of the radial stub is changed to coefficient of $-21.7 \mathrm{~dB}$. The $-10 \mathrm{~dB}$ frequency is available at $624 \mathrm{MHz}$. The simulated response of the taper line for the reflection coefficient in Figure 5 is similar to the calculated response in Figure 3, with a difference in $\Gamma_{m}$.

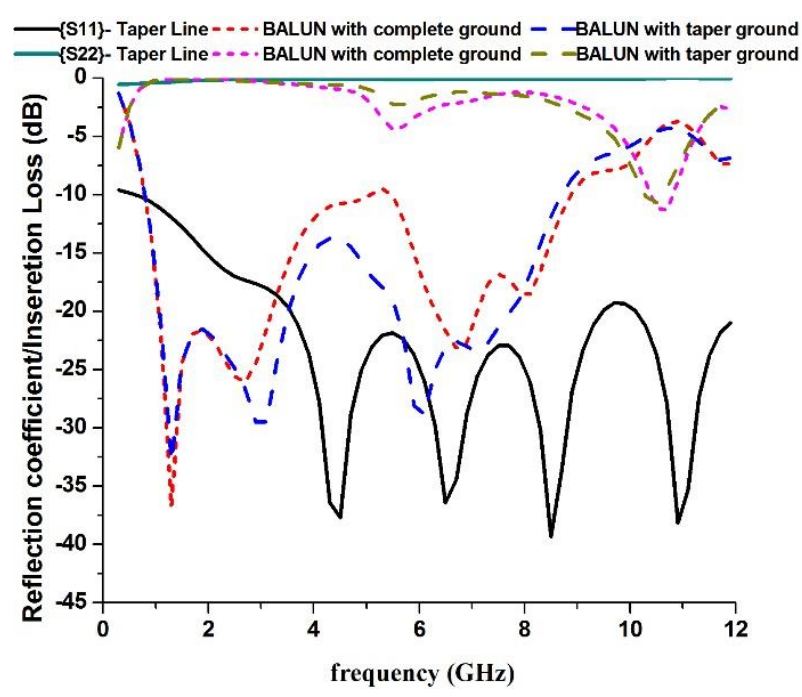

Figure 5. Frequency V/S reflection coefficient of taper line, and BALUN transformer

$7.5 \mathrm{~mm}$ only after multiple simulations to obtain optimum performance from the BALUN for the assumed band. Figure 5 shows that the electrical band spans from $800 \mathrm{MHz}$ to $8.7 \mathrm{GHz}$ with an insertion loss of $-3.2 \mathrm{~dB}$ at $6.1 \mathrm{GHz}$. The inclusion of taper ground improves $S_{21}$ and is less than $-3 \mathrm{~dB}$ for the band. The shape of the taper ground plane is shown in Figure 4. The CPS length is found to influence the performance of the BALUN significantly, and the \% bandwidth of 166 is obtained only for the CSP line of length $11 \mathrm{~mm}$. The total length of the BALUN is

MS line + taper line + CPS line $=5+30+11=46 \mathrm{~mm}$

\section{DESIGN OF PROPOSED COMPACT BALUN}

To reduce the size of the BALUN, the tapered section comprising 20 small MS lines is changed into a curved structure. The proposed structure of the tapered transmission line is shown in Figure 6 and 
is compared with the straight taper line. The complete proposed reduced size BALUN is shown in Figure 7. It comprises an MS line, taper-curved MS line and CPS line. The input is applied to the MS line and is expressed as input port-1, while the output is taken at the balanced port (i.e. at the CPS line), which is expressed as output port- 2 . The dimensions of the proposed structure and the shape of the ground plane are shown in Figure 7. The first and the last two sections of the tapered line are kept as they are to avoid any abrupt change in the entire structure between the MS and CPS lines. The total length of the remaining 17 sections is $27 \mathrm{~mm}$. This length is changed into a curved structure whose outer radius is equal to $27 / \pi$ (i.e. $8.2 \mathrm{~mm}$ ) as it is half of a complete circle. Since one end of the

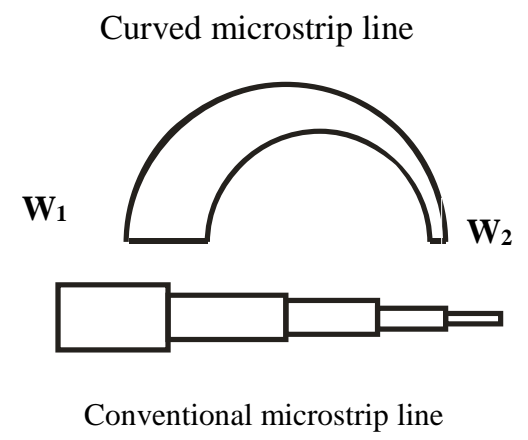

Figure 6. Proposed taper curved MS line and conventional taper line

It can be observed in Figure 4 that all the taper sections are connected along a straight line and there is a smooth transition in the cross-sectional dimension of the taper line. To have a smooth transition from section ' 1 ' to ' 2 ' in the proposed BALUN, section ' 1 ' is slightly tapered; its impact on the BALUN performance is shown in Figure 8 . There is no change in the insertion loss with this taper section, but a small taper line is wider than the other end, the structure of the curved line is also kept tapered and width $W_{1}$ is larger than the width $\mathrm{W}_{2}$, Figure 6 . The width $\mathrm{W}_{2}$ is taken as $0.34 \mathrm{~mm}$, which is equal to the width of the $19^{\text {th }}$ section of the taper line. The width $\mathrm{W}_{1}$ is kept equal to the width of the second section and is $1.4 \mathrm{~mm}$. The first section is kept as it is and is aligned with the MS line shown in Figure 7. The radius of the stub is kept at $7.5 \mathrm{~mm}$. The proposed compact BALUN with a curved MS line of radius 8.2 is simulated for an $8.5 \mathrm{~mm}$ radius for analysis purposes. It is observed in Fig. 8 that the reflection coefficient is very poor from $5.5 \mathrm{GHz}$ to $6.2 \mathrm{GHz}$. It is observed that not only the reflection coefficient but also the insertion loss is larger than $-3 \mathrm{~dB}$ from $5.7 \mathrm{GHz}$ to $6.3 \mathrm{GHz}$.

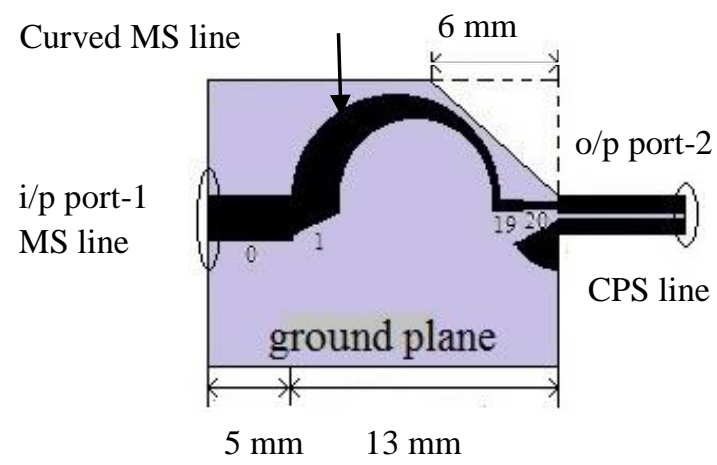

Figure 7. The proposed BALUN transformer with a tapered ground plane

improvement is observed in the reflection coefficient from $5.5 \mathrm{GHz}$ to $6.2 \mathrm{GHz}$. To have a smooth transition of the electric field from the MS line to CPS line, the upper part of the ground plane is also tapered, as shown in Figure 7. This also ensures the similarity between structures of the conventional BALUN shown in Figure 4 and the proposed BALUN shown in Figure 7. 


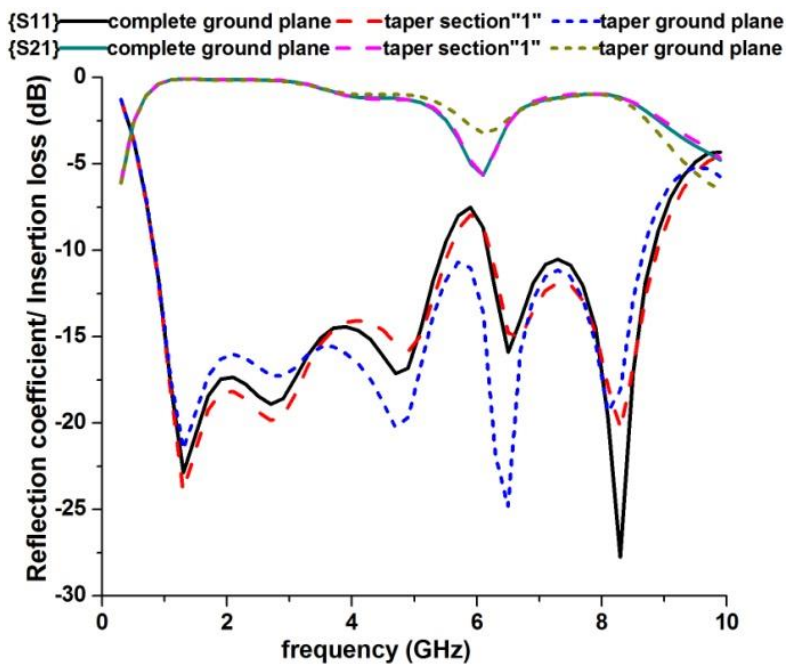

Figure 8. Result of frequency V/S reflection coefficient/insertion loss for a radius of MS line of $8.5 \mathrm{~mm}$

It can be observed in Figure 8 that the taper ground structure influences the overall performance significantly. The reflection coefficient is well below $-10 \mathrm{~dB}$ from $0.844 \mathrm{GHz}$ to $8.66 \mathrm{GHz}$. The taper ground plane also improves the insertion loss, and the maximum insertion loss observed is $-3.18 \mathrm{~dB}$ at $6.1 \mathrm{GHz}$. The proposed structure with a tapered section ' 1 ' and ground plane works well as a BALUN transformer. It is observed only after multiple simulations that the CPS length can be reduced to $10 \mathrm{~mm}$ while maintaining the optimum performance of the proposed BALUN.

To analyse the impact of the outer radius of the curved MS line on the performance of the proposed structure, different outer radii of the curved MS line are taken for simulation, keeping widths $\mathrm{W}_{1}$ and $\mathrm{W}_{2}$, the stub radius and the CPS length constant. The reflection coefficient and insertion loss of the proposed BALUN for the different outer radii of the curved MS line are shown in Figure 9. It can be observed that, when the radius of the MS line is $3 \mathrm{~mm}$, there are two bands available, one from $1.21 \mathrm{GHz}$ to $5.41 \mathrm{GHz}$, and the other from $6 \mathrm{GHz}$ to $9.2 \mathrm{GHz}$. The insertion loss for this band is less than $-3 \mathrm{~dB}$. The reflection coefficient from $5.41 \mathrm{GHz}$ to
$6 \mathrm{GHz}$ is $-9.7 \mathrm{~dB}$, and if it is considered approximately equal to $-10 \mathrm{~dB}$, then there is a complete $-10 \mathrm{~dB}$ band available from $1.21 \mathrm{GHz}$ to $9.2 \mathrm{GHz}$ with a \% bandwidth of around 154 . The $\%$ bandwidth improves to 157 when the radius increases to $4 \mathrm{~mm}$. There is an increase in the insertion loss from $9.1 \mathrm{GHz}$ to $9.6 \mathrm{GHz}$. Therefore a $-10 \mathrm{~dB}$ bandwidth with insertion loss less than $-3 \mathrm{~dB}$ is available from $1.06 \mathrm{GHz}$ to 9.1 GHz. The further increase in the outer radius of the curved MS line to $5 \mathrm{~mm}$ improves the $\%$ bandwidth to 161.5 with insertion loss less than $-2.2 \mathrm{~dB}$. The curved MS line with a radius of $5 \mathrm{~mm}$ gives the widest bandwidth for minimum insertion loss.

Reduction in the radius of the curved MS line below $3 \mathrm{~mm}$ reduces the bandwidth of the BALUN and increases the insertion loss. A summary of the electrical performance under different radii of the curved MS line of the compact BALUN is tabulated in Table 3. The length of the CPS line is taken as $10 \mathrm{~mm}$ for all the cases covered, and this provides the optimum result. The total length of the proposed BALUN is curved MS line + length of two end sections of tapered line + CPS length, that is, $10+3+10=23 \mathrm{~mm}$. In contrast, the conventional BALUN has length 
$($ tapered line $20 * 1.5) 30+11($ CPS line $)=$ $41 \mathrm{~mm}$. A $5 \mathrm{~mm}$ length of MS line accommodating the SMA connector was discarded in both cases.

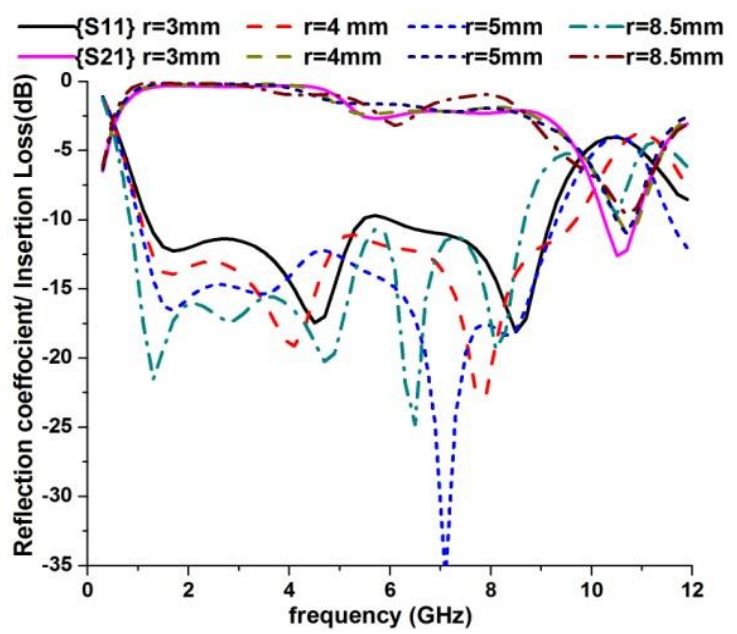

Figure 9. Result of frequency V/S reflection coefficient/insertion loss for different radius of MS

Table 3. Comparative analysis of the proposed BALUN for different radius of curved MS line

\begin{tabular}{ccccc}
\hline $\begin{array}{c}\text { Radius (MS Line) } \\
\mathrm{mm}\end{array}$ & $\begin{array}{c}f_{u-f} f_{l} \mathrm{GHz} \\
(-10 \mathrm{~dB})\end{array}$ & BW GHz & $\% \mathrm{BW}$ & $\mathrm{S}_{21} \mathrm{~dB}$ \\
\hline 8 & $8.66-0.84$ & 7.82 & 165 & -3.18 \\
\hline 5 & $9.3-0.99$ & 8.31 & 161.5 & -2.2 \\
\hline 4 & $9.6-1.06$ & 7.66 & 157 & -4.7 \\
\hline \multirow{2}{*}{3} & $5.41-1.21$ & 4.2 & 127 & -2.7 \\
\hline
\end{tabular}

To design the proposed BALUN transformer, the following steps apply once the length of taper line is fixed:

1. Using the Klopfenstein taper relation to determine the impedance of the first two and last two sections of a taper line and calculate the width of these sections.

2. The radius of the outer curved MS line $=($ Length of taper line - length of three sections of taper line) $/ \pi$. Choosing $\mathrm{W}_{1}$ as the width of the $\mathrm{N}_{2}$ section and $\mathrm{W}_{2}$ as the width of the $(\mathrm{N}-1)$ section. $\mathrm{N}_{2}$ is the second section of tapered line and $\mathrm{N}$ is total sections.

3. Choosing CPS line length can be chosen for maximum bandwidth and minimum insertion loss.
4. Further reducing the radius of the curved MS line to have the smallest possible size of the overall BALUN.

\section{RESULTS AND DISCUSSION}

The conventional and proposed compact BALUNs were simulated using CST STUDIO and developed on FR-4. Both the BALUNs were measured using a vector network analyser. There were four different cases of proposed BALUNs, but the BALUN with a curved MS line with a 5 $\mathrm{mm}$ radius was manufactured. The BALUN with this radius gives the largest bandwidth and the smallest insertion loss. Figure 10 shows a photograph of the BALUNs. Both were loaded with a $100 \Omega$ SMD resistor at 
the output port. The measured results of both the BALUNs, along with the simulated results, are shown in Figure 11. The conventional BALUN shows complete band coverage from $0.87 \mathrm{GHz}$ to $9 \mathrm{GHz}$. $\mathrm{S}_{21}$ is not included because BALUNs are designed as a single port device. The \% bandwidth for the conventional BALUN is 165. The measurement of the proposed BALUN shows that the \% bandwidth was $159 \%$ for the frequency range from $1.1 \mathrm{GHz}$ to $9.65 \mathrm{GHz}$.

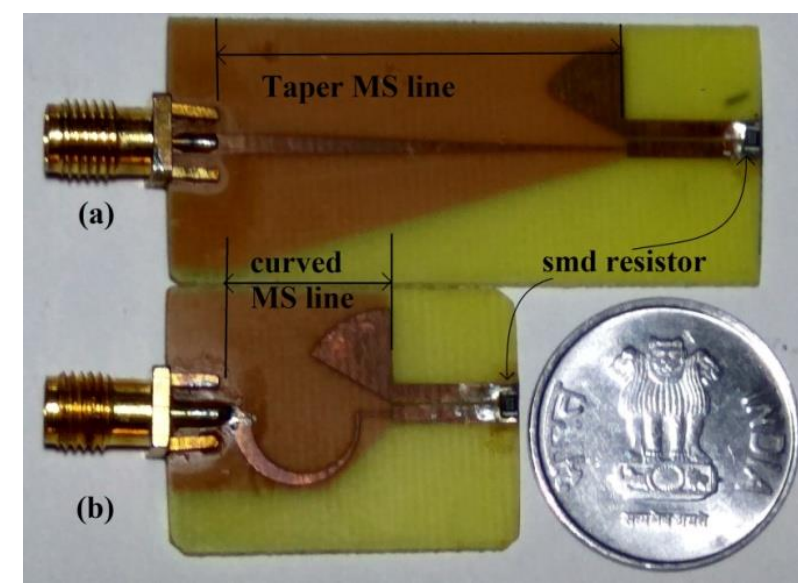

Figure 10. Photograph of (a) conventional BALUN and (b) proposed compact BALUN

Table 4 compares the simulated results of all the proposed BALUNs with the conventional BALUN in terms of $\%$ bandwidth and length. The comparison was done only for the taper lines from conventional and proposed BALUNs. It can be observed that, when the length of the taper MS line of the proposed BALUN (curved $\mathrm{L}=19 \mathrm{~mm}$ ) is equal to the taper

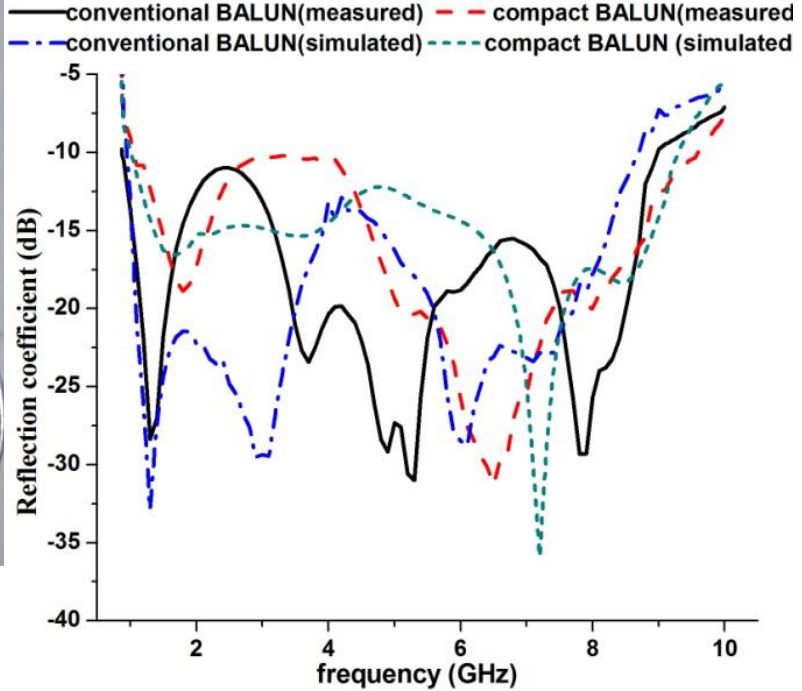

Figure 11. Measured and simulated results of conventional and compact BALUNs

length of the conventional BALUN (straight $\mathrm{L}=30 \mathrm{~mm}$ ), the length of the proposed BALUN reduces to only $36 \%$ w.r.t. the conventional BALUN. The \% bandwidth of the proposed BALUN is 165 and the $\%$ bandwidth of the conventional BALUN is 166 . The maximum reduction in taper line length is $73 \%$ but at the cost of a $\%$ bandwidth reduction of 13 .

Table 4. Comparison of taper line length from conventional and proposed BALUNs

\begin{tabular}{lccccc}
\hline BALUN parameters & $\begin{array}{c}\text { Conventional } \\
\text { BALUN }\end{array}$ & \multicolumn{3}{c}{ Proposed length of curved taper line (mm) } \\
\hline Length $(\mathrm{L})$ & 30 & 9 & 11 & 13 & 19 \\
\hline Bandwidth $(\mathrm{GHz})$ & 7.9 & 7.99 & 7.66 & 9.31 & 7.82 \\
\hline \% Bandwidth & 166 & 153 & 157 & 161.5 & 165 \\
\hline \% Size Reduction & ------- & 73 & 63 & 56.7 & 36 \\
\hline
\end{tabular}

The comparison between the proposed BALUN and other existing BALUNs is included in Table 5. In the table, the length of the proposed BALUN represents the length of the taper line only.
When a CPS line of length $10 \mathrm{~mm}$ is added to the curved taper line, the total length of the BALUN is extended by $10 \mathrm{~mm}$. It can be observed that the proposed structure of the BALUN outperforms all the BALUNs 
in terms of size and \% bandwidth, excluding the BALUNs given by Bah (2016), Lin et al. (2015) and Lee et al. (2018). These three BALUNs are smaller than the proposed curved BALUN. The proposed curved BALUN outperforms the
BALUN proposed by Lee et al. (2018) in terms of $\%$ bandwidth. Another advantage of the proposed BALUN over these three BALUNs is that it does not require vias and is simple to manufacture.

Table 5. Performance comparison of proposed BALUN with existing BALUNs

\begin{tabular}{|c|c|c|c|c|c|c|c|c|c|c|}
\hline 章 & D & $\sim$ & 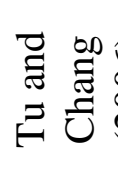 & 䨔 & 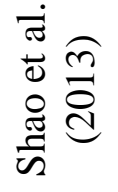 & 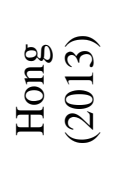 & 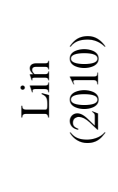 & 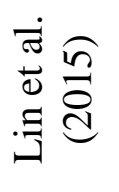 & 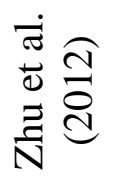 & 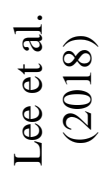 \\
\hline $\begin{array}{l}f_{1-} f_{\mathrm{h}} \\
\mathrm{GHz}\end{array}$ & $\begin{array}{c}1.1 \\
- \\
9.6 \\
5\end{array}$ & $\begin{array}{c}0.84 \\
- \\
8.66\end{array}$ & $\begin{array}{l}2.7- \\
10.4\end{array}$ & $0.7-15$ & $\begin{array}{c}0.72 \\
- \\
2.05\end{array}$ & $\begin{array}{c}0.5- \\
5\end{array}$ & $2.4-6$ & $\begin{array}{l}3.6- \\
10.7\end{array}$ & $\begin{array}{l}3.1- \\
10.6\end{array}$ & $6-40$ \\
\hline $\begin{array}{l}\% \mathrm{~B} \\
\mathrm{~W}\end{array}$ & $\begin{array}{c}15 \\
9 \\
\end{array}$ & 165 & 118 & 175 & 96 & 164 & 86 & 99.3 & 110 & 148 \\
\hline $\begin{array}{c}\mathrm{L} \\
\mathrm{mm}\end{array}$ & 13 & 19 & 23.3 & 25.5 & 71 & 34.1 & 25.8 & 10.5 & 20 & 13 \\
\hline Year & $\begin{array}{l}---- \\
---\end{array}$ & ---- & 2006 & 2016 & 2013 & 2013 & 2010 & 2015 & 2012 & 2018 \\
\hline
\end{tabular}

$f_{1}$, lower cut-off frequency; $f_{\mathrm{h}}$, upper cut-off frequency; BW, bandwidth, $\mathrm{P}$, proposed

\section{CONCLUSION}

The Klopfenstein taper line is already a compact line used to transform impedance, but the proposed technique can be used to reduce this line further. It is found that the proposed method reduces the size of the BALUN by $56.7 \%$ at the cost of $4.5 \%$ reduction in the bandwidth of the proposed BALUN as compared to the conventional BALUN. The size of the BALUN can be reduced to $73 \%$ w.r.t. the conventional BALUN at the cost of $\%$ bandwidth. The $\%$ bandwidth drops by $13 \%$ for the maximum reduction of $73 \%$ in the size of the BALUN. This technique can be applied to other existing straight BALUNs, and a further reduction in size can be achieved. This product can be helpful for feeding any balanced antenna without occupying much area on the PCB.

\section{ACKNOWLEDGEMENTS}

The authors are very thankful to $\mathrm{Mr}$ Shivraj for providing the measurement facility for the designed products.

\section{REFERENCES}

Anagnostou, D. E., Morton, M., Papapolymerou, J., \& Christodoulou C. G. (2008). A 0$55 \mathrm{GHz}$ coplanar waveguide to coplanar strip transition. IEEE Transactions on Microwave Theory and Techniques, 56, 1-6.

Bah, A. O. (2016, September). An extremely wideband tapered balun for application in tightly coupled arrays. In 6th IEEE-APS Topical 
Conference on Antennas and Propagation in Wireless Communications (pp. 162-165). IEEE>

Hong Y.-P. (2013). Fat dipole antenna with broadband balun using CPW-toslotline field transformation. Electronics Letters, 49, 635-636.

Klopfenstein, R. W. (1956, January). A transmission line of improved design. In Proceedings of the I.R.E. (pp. 31-35).

Lee, H. G., Mohyuddin, W., Choi C. H., \& Kim K. W. (2018). Asymmetric ultra-wideband microstrip-tocoplanar stripline transition. IEEE Microwave and Wireless Components Letters, 28(5).

Lin, S., Wang, J., Deng, Y., \& Zhang, G. (2015). A new compact ultrawideband balun for printed balanced antennas. Journal of Electromagnetic Waves and Applications, 29, 1570-1579.

Lin, S.-C. (2010). Wideband series-fed dipole antenna with balun integrated. Journal of Electromagnetic Waves and Applications, 24, 2463-2477.

Maksimovitch, Y., Mikhnev, V., \& Vainikainen, P. (2007, September). Step-by-Step modification of Printed Wideband Balun for GPR Antennas. In17th International Conference on Microwave and Telecommunication Technology (pp. 427-428). IEEE.

Meng, X., Wu, B., Huang, Z., \& Wu, X. (2016). Compact 30:1 bandwidth ratio Balun for printed balanced antennas. Progress in Electromagnetics Research C, 64, 125-132.
Pozar, D. M. (1998). Microwave engineering. John Wiley \& Sons.

Resley, L., \& Song, H. (2012). Ka-band Klopfenstein tapered impedance transformer for radar applications. Progress in Electromagnetics Research, 27, 253-263.

Ruvio, G., \& Ammann, M. J. (2008, July). Effects of Klopfenstein tapered feedlines on the frequency and time domain performance of planar monopole UWB antennas. In IEEE Antennas and Propagation Society, International Symposium (pp. 1-4). IEEE.

Shao, J., Zhou, R., Chen, C., Wang, X., Kim, H., \& Zhang, H. (2013). Design of a wideband Balun using parallel strips. IEEE Microwave and Wireless Components Letters, 23, 125-127.

Tu, W.-H., \& Chang, K. (2006). Wide-band microstrip-to-coplanar stripline/slotline transitions. IEEE Transactions on Microwave Theory and Techniques, 54, 1084-1089.

Vega, F., Mora, N., \& Rachidi, F. (2011, September). Design and simulation of a coaxial exponential transmission line for a half impulse radiating antenna. In 2011 XXXth URSI General Assembly and Scientific Symposium (pp. 1-4). IEEE.

Zhu, F., Hong, W., Chen, J., \& Wu, K. (2012). Ultra-wideband single and dual Baluns based on substrate integrated coaxial line technology. IEEE Transactions on Microwave Theory and Techniques, 60, 3062307. 